\title{
Temporal scale of field experiments in benthic ecology
}

\author{
Jenkins, Stuart; Yrayzoz, Marc Uya
}

\section{Marine Ecology: progress series}

DOI:

$10.3354 /$ meps 11659

Published: 01/04/2016

Peer reviewed version

Cyswllt i'r cyhoeddiad / Link to publication

Dyfyniad o'r fersiwn a gyhoeddwyd / Citation for published version (APA):

Jenkins, S., \& Yrayzoz, M. U. (2016). Temporal scale of field experiments in benthic ecology. Marine Ecology: progress series, 547, 273-286. https://doi.org/10.3354/meps11659

\footnotetext{
Hawliau Cyffredinol / General rights

Copyright and moral rights for the publications made accessible in the public portal are retained by the authors and/or other copyright owners and it is a condition of accessing publications that users recognise and abide by the legal requirements associated with these rights.

- Users may download and print one copy of any publication from the public portal for the purpose of private study or research.

- You may not further distribute the material or use it for any profit-making activity or commercial gain

- You may freely distribute the URL identifying the publication in the public portal ?
}

Take down policy

If you believe that this document breaches copyright please contact us providing details, and we will remove access to the work immediately and investigate your claim. 
3 School of Ocean Sciences, Bangor University, Menai Bridge, Anglesey, UK LL59 5AB

4

5

Running head: Duration of experiments in benthic ecology

7

8

Email: s.jenkins@bangor.ac.uk

9 
The issue of scale in ecology is all-pervasive, with recognition that most ecological questions are scale dependent. Scaling up has become part of the lexicon of experimental ecology, and in marine benthic systems has resulted in numerous advances. While it is clear that manipulative experiments in benthic systems have been conducted over increasing spatial scales, it is less clear whether the notion of scaling up has been applied to temporal scale. Here, we examine the temporal scale at which experiments have been undertaken before reviewing longer term studies to examine the insights gained from extending the duration of observation following perturbation. Field experiments which examined population/community responses to perturbations, and studies which monitored the consequences of natural disturbances, were identified over the period 1980-2013. The median length of study was 10 months and only $12 \%$ of studies were carried out over more than 3 years. Neither the median study length, nor the proportion of studies longer than 2 or 3 years, showed a trend over the 33 years. Review of experiments with a duration of 3 years or more revealed numerous benefits of a long-term approach. Some of these were unexpected, but others were predictable based on life history traits of dominant organisms, slow successional patterns, or response variables related to longer term community level responses, such as stability. The review suggests modest investment in resources to extend the duration of experiments can bring substantial benefits and hence consideration of experimental duration should be one of the primary decisions in planning field experiments.

Keywords: field experiments; long term; perturbation; scaling up; temporal scale 


\section{Introduction}

Our understanding of ecological processes in the marine benthic environment has been built on a foundation of manipulative experiments over the past half century or so, in a range of intertidal and shallow sub-tidal systems. Both soft and hard substrata habitats have been utilised by experimental ecologists, intent on understanding the processes structuring marine assemblages, and hence explaining patterns in abundance, distribution and diversity of species (see Raffaelli \& Hawkins 1996 for review). Marine ecological experiments have also contributed to important advances in ecological theory (e.g. Connell 1961, Paine 1966, Dayton 1975, Menge \& Sutherland 1976, Bertness \& Callaway 1994). The intertidal zone is favoured by experimental ecologists owing to the logistical ease of working on marine communities when the tide is out, combined with a sharp marine/terrestrial environmental gradient which is conducive to investigations of the interaction of physical and biological processes. Additionally, the intertidal is inhabited by organisms which are generally small and sessile/slow moving and hence amenable to experimental manipulation (Connell 1972, Paine 1977, Underwood 2000) and in the case of hard substrate, the environment is twodimensional in nature. Sub-tidal work is more challenging, but there is still a vast body of experimental research undertaken in this environment, either through the use of SCUBA or suspending experiments from floating or fixed structures. Focal habitats for experimental research in the coastal zone include coral reefs, seagrass beds, subtidal rocky reefs, intertidal rocky shores, mud-flats and beaches and sub-tidal soft sediment systems.

The development of experimental ecology in marine systems and the advances made over the past 50 years or so are well documented (see Paine 1994, Underwood 2000, Castilla 2000 for reviews). One area which has received increasing attention, in marine as well as terrestrial and freshwater habitats, is the issue of scale (Wiens 1989, Levin 1992, Schneider 2001, Ellis $\&$ Schneider 2008). Schneider (2001) neatly summarised three components to the problem of scale: problems in ecology often exist at decadal time scales over large ecosystems; most variables can only be measured in small areas over short time scales; patterns and processes observed at small scales do not necessarily hold at large scales. It is increasingly recognised that environmental drivers and ecological processes operate over a range of different spatial and temporal scales and over the past two decades, scale, in a quantitative sense, has been increasingly incorporated into experimental work (Ellis \& Schneider 2008). 
Ecologists in coastal marine systems have been key in developing a framework in which understanding from manipulative experiments may be scaled up through the comparative experimental approach (Menge et al. 2002). Identical replicated experiments are conducted at multiple sites often over some environmental gradient (e.g. Menge et al. 1997, Jenkins et al. 2001, Coleman et al. 2006), thus allowing determination of the extent to which large scale physical conditions, which are not amenable to manipulation, can modify ecological processes. This 'scaling up' approach has led to a number of important developments in understanding of coastal systems, particularly in recognising the importance of latitudinal variation in temperature (e.g. Leonard 1999, Sanford 1999, Jenkins et al. 2001), regional variation in productivity (Menge et al. 1997, Broitman et al. 2001) and large scale variation in recruitment regime (Connolly \& Roughgarden 1998). Studies of systems in contrasting oceanographic regimes have made progress in integrating small, medium and large scale processes and in particular have shown that benthic assemblages in shallow water or intertidal areas do not operate in isolation from the planktonic, pelagic realm (Menge et al. 2003).

In considering scale, attention has not solely focused on variation in space, with increasingly sophisticated ecological experiments examining processes at a range of different temporal scales. For example the importance of seasonality in determining the magnitude and direction of ecological processes is now recognised in experiments through manipulations being performed at different times of the year, and it is not uncommon for multiple starting dates to be nested within season in order to provide unconfounded tests of seasonal effects (e.g. Jenkins et al. 2005). Another aspect of temporal scale is the variability of events through time. Benedetti-Cecchi (2003) highlighted that temporal variability in the occurrence of perturbations is generally expressed in terms of the frequency of events, but argues that a more appropriate approach which avoids confounding the variance with the mean effect size (i.e. a more frequent disturbance is also more intense) is to design experiments in which levels of intensity, and those of variability, are chosen independently. His work has led to numerous studies explicitly assessing the importance of temporal variance in perturbations (e.g. Incera et al. 2010, Maggi et al. 2012, Oliveira et al. 2014).

Consideration of temporal scale also clearly needs to take account of the duration of any particular manipulative experiment. Underwood (2000), based on the assertion of Connell \& Sousa (1983) that studies should encompass a period as long as the turnover of individuals in resident species, suggests that on Australian rocky shores a period of between 5 and 7 years might be appropriate, but also considers studies may need to be much longer to allow analyses 
of equilibria. Yodzis (1988) considered that for the impact of a press perturbation to be known, a long term approach is required. He recommended adopting a rule of thumb such that the time scale of observation should approximate to two times the sum of the generation times of a pressed species (i.e. one whose density has been modified) and the potentially impacted species of interest. It is debateable whether all experiments require such duration, and clearly there are specific questions which can be addressed by much shorter studies. For example Menge (1997) tested the assertion that indirect effects may take longer to become apparent, following a manipulation, than direct effects, by determining the relationship between duration of experiment and the importance of indirect effects using 23 rocky intertidal interaction webs. He concluded that in the case studies examined, which ranged in length from 0.5 to 156 months, 'interpretations of community dynamics are not likely to be distorted because experiments were too brief' (p.812). Thus, based on addressing a very specific goal, that of quantifying indirect effects in community dynamics, Menge (1997) considered the experiments he reviewed as being sufficiently long.

In most fields of marine benthic ecology there has been a lack of explicit consideration of experimental duration. A field of burgeoning research that has recently recognised the serious implications of a short term approach is in Biodiversity and Ecosystem Functioning (BEF) work (Hooper et al. 2005, O’Connor \& Crowe 2005, Raffaelli 2006, Crowe et al. 2012, Duffy et al. 2012). Crowe et al. (2012) used existing meta-analyses (Cardinale et al. 2007, Stachowicz et al. 2007) to review the temporal scale of biodiversity-ecosystem functioning (BEF) studies conducted in both laboratory and field settings (in marine, terrestrial and freshwater environments). The authors argue that limiting the temporal extent of experiments has a marked effect on the conclusions regarding the importance of biodiversity in ecosystems and the mechanism by which biodiversity may exert an effect; short term experiments will over-emphasise the importance of dominant species (a species identity effect) relative to complementarity among species. Stachowicz et al. (2008a) examined the effect of seaweed diversity on cover over a period of three years. They showed that seaweed cover in diverse treatments only exceeded that in the best performing monoculture after a period of 18 months, a period much longer than many biodiversity studies (Crowe et al. 2012). These observations might reasonably be seen as strong arguments for lengthening the duration of BEF experiments (although doing so in any multi-trophic manner incorporating large, mobile long lived consumers will be enormously challenging (Raffaelli 2006)). 
Although many aspects of temporal scale have been addressed through ecological experiments in recent decades, it is debateable whether the scaling up approach, so prevalent in considerations of spatial scale, has been applied to temporal scale. Thus it is unclear whether the overall length of experimental study (i.e. scaling up in time) has increased, despite numerous publications tentatively expressing concern at the paucity of longer term experimentation (e.g. Connell \& Sousa 1983, Underwood 2000, Raffaelli 2006). Such calls have no doubt been influenced by the perceived benefits of long term experimentation (Underwood 2000; Crowe et al 2012). Here, we examine the temporal scale at which ecological experiments (which apply some form of perturbation) are undertaken in intertidal and shallow sub-littoral environments before reviewing the literature to highlight the range of insights gained from long term experiments. We finish by considering the challenges associated with increasing the temporal extent of marine benthic experiments and the way in which these may be addressed.

\section{Review of experimental duration}

As outlined above there have been a number of calls for longer term experimentation, but a factor which may act counter to such a move is the increasing pressure on scientists to publish their work. While publication of research in a vibrant international literature is the life-blood of science, the pressure to publish could be argued to lead to a short term approach, with researchers rushing to publish each new piece of research. It is very easy to see how this short term approach can influence our approach to experimental ecology. Why spend 5 years undertaking an experiment when a paper can be published on the basis of results collected over a period of 18 months? By reviewing the literature (including both marine focused and general ecological journals) we hope to determine what range of temporal scales experimental marine ecologists are working at and whether the approach to experimental duration has changed over a 33 year period. This review is limited to assessment of the effects of perturbation on marine systems; thus long term monitoring per se is not considered although it is acknowledged that this approach may often address similar questions.

\section{Methods}

We examined literature published over a 33 year period in two of the leading marine ecological journals, Marine Ecology Progress Series (MEPS) and Journal of Experimental Marine Biology and Ecology (JEMBE), and three general ecological journals, Ecology, Oikos and Oecologia in order to examine the temporal scale and sampling frequency of field 
perturbation experiments in shallow sub-tidal and intertidal benthic environments. In selecting publications, all types of pulse and press perturbations were included, from manipulations which simulate some form of natural or anthropogenic disturbance event, to those in which the density or presence of one or more particular species is altered. In addition to manipulation of biota we included perturbations to the physical environment, for example modification of the nutrient or light regime. One very common type of study was one in which new substrata (often simple PVC panels) were introduced into the environment. Such perturbations may be considered analogous to clearance of biota in natural communities, since both provide bare space, free from competitors.

In considering which studies to include, the main criterion beyond inclusion of an appropriate perturbation was the response variable measured. In general, studies were included which measured the community or population response of macro-organisms to a perturbation (i.e. meiofauna and microbial communities were rejected). Studies where the research aim was solely to examine some process rate, such as growth or mortality, or the effect of disturbance on an organisms' body condition, were excluded. In addition, studies which examined only a behavioural response were not included. One difficult judgement to be made was in studies designed to examine spatial or temporal patterns in the arrival of animals or algae i.e. settlement/recruitment. Where the aims of such work were only short term in nature, i.e. examination of settlement, such studies were not included since settlement can be clearly defined as a short term process (Jenkins et al. 2009). However, use of the term recruitment is more problematic. Because of its variable use in benthic ecology with no defined time period over which it applies (Keough \& Downes 1982, Jenkins et al. 2009) studies examining recruitment were included unless the aim of the study was clearly related to understanding processes determining the arrival of propagules and subsequent settlement (e.g. Reinhardt et al. 2013) rather than the development of a benthic population or community.

In addition to manipulative experiments implemented by the experimenter, numerous studies examine the consequences of events or implementation of management structures not under the control of the experimenter. These include investigations of natural disturbances such as extreme weather events (e.g. Tegner et al. 1997) or human-induced perturbations such as pollution (e.g. Jacobs 1980), the exclusion of humans from Marine Protected Areas (Castilla \& Bustamante 1989) and managed realignment of coastal limits through intentional flooding (Hughes et al. 2009). These `natural experiments`were included in our review of literature 
whenever data were available prior to the perturbation taking place, such that a true temporal control existed.

Using the criteria outlined above, all publications in MEPS, JEMBE, Ecology, Oikos and Oecologia at four yearly intervals from 1981 to 2013 were initially reviewed by examination of the title and abstract. Following identification of potential papers the full text was read and then either rejected or the appropriate information extracted. This approach was taken rather than performing a search based on keywords because of the difficulty in creating suitable search terms which would highlight appropriate papers without bias. Our search through 12,557 titles (6940 in general ecological journals; 5617 in marine ecological journals) identified a total of 263 publications containing 322 independent experiments over the nine publication years. These represented an average of 3.5\% and $1.3 \%$ of the studies published in marine and general ecological journals respectively (or 15.9\% of the marine related papers published in general journals). Although there was no obvious directional change over the 33 years of review in the proportion of appropriate studies selected in each year in either journal type, there was a general increase in the number of studies from which data were extracted owing to the huge increase in number of publications in all journals over time (from 299/564 in 1981 to $823 / 831$ in 2013 for marine/general ecological journals respectively). In order to allow good representation of experimental work in earlier years, additional publications were sought for the earliest five dates by examining studies published up to two years before (and in the case of 1981, two years after). This approach was taken in the same way as described above, until a minimum of 10 independent experiments in both marine ecological and general ecological journals were identified for each of the four-yearly periods. This resulted in 293 publications containing 352 studies being reviewed.

The temporal scale of experiments in all 352 studies was determined as the length of time from initial sampling, immediately prior to the perturbation, to the final sampling event. Where multiple experiments within a single publication were conducted with the aim to examine a single goal or hypothesis, the maximum length of experimentation was documented. In determining the sampling interval (i.e. length of time between each sampling event) an average value over the period of the study was calculated. For example, in a ten month study examining the influence of bivalve shell material introduced to a mudflat on colonisation by burrowing thalassinidean shrimp, Feldman et al. (1997) made observations 1 month after the perturbation and after ten months. Here, the average sampling interval was recorded as 5 months. The habitats in which experiments were undertaken were classified as 
inter-tidal or sub-tidal. In micro-tidal regimes such as the Mediterranean (e.g. Maggi et al. 2009) and Baltic (e.g. Lindegarth et al. 2001) studies undertaken in areas frequently exposed to air through variations in pressure and wind were classified as intertidal. The Caribbean fringing reef studied by Kilar \& MacLachlan (1989) is exposed to air only during particular conditions, at certain times of the year, and was therefore considered sub-tidal. The classification of habitat type (rock, soft sediment, sea-grass, coral, mangrove, salt-marsh, artificial substrate) was generally clear cut. Cobble and boulder habitat were considered simply as rock rather than creating a novel category.

Classification of experiments as pulse or press was clear-cut in most cases. Pulse experiments were defined as those receiving a one-off, perturbation which was generally short in temporal extent compared to the temporal scale of the study. The introduction of artificial substrata such as PVC panels (e.g. Valdivia et al. 2005) or newly quarried boulders (e.g. Chapman 2013) was considered a pulse disturbance, analogous in many ways to the creation of bare space by a single disturbance event. In cases where both pulse and press perturbations were implemented, the experiments were invariably classified as press. For example in numerous studies, novel substrata were introduced in order to examine the consequences of a particular press manipulation, such as light and sediment (Connell 2005) or herbivores (Kaehler \& Williams 1997). Other studies (e.g. Russell \& Connell 2005) combined pulse manipulations such as the one-off removal of a particular species with continued press perturbations such as addition of nutrients Rather than class these as a combination of both pulse and press, they were classed as press. In some studies, multiple perturbations were applied through time (Jewett et al. 2005, Incera et al. 2009, Minchinton \& Fels 2013) and again here it was considered that the principle of an ongoing perturbation (although not continuous) justified categorisation as press.

\section{$\underline{\text { Results and Discussion }}$}

$64 \%$ of the 352 studies over the 33 years were from marine journals (MEPS and JEMBE) whereas $36 \%$ were published in general ecological journals (OIKOS, Ecology, Oecologia). The studies were split almost exactly equally between the intertidal (49.7\%) and the sub-tidal $(50.3 \%)$ zones. Of the eleven different habitats identified the most common was inter-tidal rocky shore (31\% of studies) followed by sub-tidal rocky reef (14\%) and then sub-tidal artificial substrate and sub-tidal coral reef (9\% each). $62 \%$ of the studies were categorised as press (217 studies) whilst the rest were considered as pulse (135). 
Examination of the frequency distribution of study length across 33 years showed a clear skew to a shorter time frame (Figure1). The highest proportion (24\% and 33\% for marine and general ecological journals respectively) were very short (between 0 and 3 months), with obvious peaks at 9-12 and 21-24 months for marine journals (presumably due to the logical attraction of terminating experiments at one and two years respectively) (Figure 1). Most studies ( $85 \%$ for marine and $82 \%$ for general ecological journals) lasted two years or less and only 39 of the 352 studies were conducted over a period of 3 years or more. Of these, 17 studies were of a period of 5 years or more. The median length of study over the period reviewed was 11 months in marine journals, 9 months in general ecological journals and 10 months overall (Figure 2). Although the median study length varied among years for marine journals (Kruskal Wallis test, Chi-Square $=19.427 ; \mathrm{df}=8 ; \mathrm{P}=0.013$ ) there was no apparent trend in study length with time.

Study length showed differences between habitat (intertidal versus subtidal) and between perturbation type (pulse versus press) (Figure 3). The median length of inter-tidal studies (12 months) was significantly longer than sub-tidal studies (8 months ) (Mann Whitney U test: $\mathrm{Z}=-2.407 ; \mathrm{p}=0.016$ (Figure $3 \mathrm{~A}$ ). In the intertidal zone, $30 \%$ of studies were conducted over 2 years or more, approximately double that in the sub-tidal. The median study duration of pulse experiments (14 months) was significantly longer than press experiments (6 months) (Mann Whitney $\mathrm{U}$ test: $\mathrm{Z}=-4.762 ; \mathrm{p}<0.001$ ) (Figure $3 \mathrm{~A}$ ) and a far greater proportion lasted two years or longer ( $35 \%$ of pulse compared to only $16 \%$ for press).

There was a significant positive relationship between experimental duration and sampling interval $\left(\mathrm{F}_{1,347}=108.5 ; \mathrm{P}<0.001\right)$. Thus, as experiments got longer the time between sampling events increased. However, the relationship was weak $\left(r^{2}=0.236\right)$, driven partially by the fact that a sampling interval (the dependent variable) cannot be greater than the experimental duration (the predictor variable) and indeed many studies well beyond the median duration had short sampling intervals of between 0.5 and 3 months.

In discussing the need for a longer term approach Underwood (2000, p.68) states that 'the majority of ecological studies are quite short, usually three to five years'. In fact, our analysis of 352 studies over 33 years shows that for experiments (i.e. where some form of manipulation or perturbation has taken place, as opposed to purely observational work) the median length of study was only 10 months and only $12 \%$ of published work was over a period greater than 3 years. Patterns were similar irrespective of the type of journal (marine 
specific versus general ecological) in which papers were published. These results were quite clear in indicating that calls for an increase in the temporal scale of studies have not led to any general increase in experimental duration over the past 3 decades. This is true whether considering the median duration of studies or the proportion which are longer than 24 or 36 months.

Different approaches can be taken to make an argument for the benefits of longer term experimental duration. One is in demonstrating that longer term experiments reveal, for example, differences in effect sizes compared to short term experiments. Such an approach is fraught with problems in designing a non-biased analysis, since often the benefits of long term experimentation are revealed not in a single bigger outcome but in multi-faceted results which provide greater insight into ecological complexities. Below we address such complexity by reviewing a range of longer term studies (generally greater than three years) which have revealed greater insight than could be achieved by equivalent short term work.

\section{Insights from long term experiments}

\section{$\underline{\text { Controlled manipulations }}$}

There are a diversity of reasons for conducting long term experiments including: study of long lived species (e.g. Clarke \& Allaway 1993; Jenkins et al. 2004) and slow successional change (Yakovis et al 2005); work in polar regions where development rates are much slower (Konar 2007, Beuchel \& Gulliksen 2008); the search for long lived ecological phenomena such as alternate stable states (Petraitis \& Dudgeon 2005); determination of the nature and extent of temporal community fluctuations in disturbed systems (Dye 1998). Defining how long to run field experiments is a difficult task but the number of studies in marine coastal systems which show differences between control and treatment plots more than 5 years (Clarke \& Allaway 1993, Cervin et al. 2005, Viejo 2009, Schiel \& Lilley 2011) and in some cases more than 10 years (Dye 1998, Jenkins et al. 2004, Beuchel \& Gulliksen 2008) after a perturbation suggest that to address many community level questions experiments should run for years rather than months. Differences among treatments are not simply limited to community structure but also to overall community productivity (Tait \& Schiel 2011) and to community stability (Dye 1998). For example, Tait \& Schiel (2011) showed that 90 months after removal of the fucoid canopy alga Hormosira banksii, community primary productivity was only between $40 \%$ to $60 \%$ that of control areas. The reasons for slow recovery may be because successional development is inhibited (sensu Connell \& Slatyer 1977) by early colonisers (e.g. Sutherland 
\& Karlson 1977), communities are dominated by slow growing species (e.g. Jenkins et al. 2004) or the environment is conducive to slow development, for example in polar regions (e.g. Beuchel \& Gulliksen 2008).

In polar regions disturbance can have a profound effect on community structure owing to very slow, and in many cases, an almost complete lack of recovery (Dayton \& Oliver 1977, Barnes 1996, Konar 2007). For example, Konar (2007) found that 4 years after clearance of sub-tidal boulders on the Alaskan north coast, cover of biota had only reached $2 \%$, despite the fact that bare surface in the community in general was scarce $(<10 \%)$. A similar lack of colonisation (a total of 2 serpulid polychaetes present after 3 years, and reports of bare surfaces after 5 years) on a settlement panel array was observed in McMurdo Sound, Antarctica (Dayton 1989). This was followed at some point by bryozoan, hydroid, soft coral, and sponge colonisation leading to 'heavily covered' surfaces (Dayton 1989, p.1486). Low recruitment and slow growth may characterise polar regions, with physically driven episodic events driving a punctuated succession (Dayton 1989). Such an environment clearly requires long term experimental work.

One argument for conducting long term experiments is that they can reveal quite unexpected results. Jenkins et al. (1999a,b, 2004) report the results of factorial manipulations of the long lived canopy species Ascophyllum nodosum and the keystone grazer Patella vulgata on sheltered canopy dominated shores of the Isle of Man. Short term results over a period of one to two years included the die back of understorey turfing algae, opening up of bare space and replacement of the Ascophyllum canopy with alternative more opportunistic shorter lived fucoid species, Fucus vesiculosus and F.serratus. However it was the longer term observations over 6 years (Jenkins et al. 1999a) and then twelve years (Jenkins et al. 2004) which revealed the importance of Ascophyllum in limiting patellid limpet populations; loss of the facilitatory function of the canopy on understorey turfing algae, and hence the opening up of bare space, resulted in enhancement of limpet recruitment, leading to populations up to six times greater in abundance over a decade after canopy loss. Here, experimental work demonstrated the stabilising function of turfing algae in the undisturbed community. Other work has recognised how the dense low lying nature of turfing algae, combined with sediment trapping ability (Connell et al. 2014) contributes to stability or slow succession (e.g. Cervin et al. 2005, Schiel \& Lilley 2011). 
It is frequently stated that coastal marine systems are ideal environments in which to conduct manipulative experiments because dominant organisms have relatively short generation times and hence experiments may be conducted over short time scales. However it is debatable whether generation times in primary producers, key consumers and dominant space occupiers (which are often a number of years) are short enough to justify this view (Beuchel \& Gulliksen 2008). Species life history traits are important determinants for the recovery of communities following disturbance in a range of different ecosystems including saltmarshes (e.g. Bertness 1991), mangroves (e.g. Clarke \& Allaway 1993) and rocky shores (e.g. Methratta \& Petraitis 2008), and species longevity, as well as mode and rate of colonisation, have clear implications for experimental duration. Methratta \& Petraitis (2008) examined recovery from disturbance on rocky shores focusing on species with contrasting longevities, barnacles and fucoid algae. They showed that differences in life history traits of dominant species modified successional trajectories at different spatial scales over a 5 year period. Understanding of the population dynamics and community structuring role of long lived species will invariably require longer term studies than investigation into species with short generation times, clearly demonstrated by the nine year study on mangrove regeneration of Clarke \& Allaway (1993) and the three year study of Bertness (1991) on Spartina competitive interactions. On rocky shores Ascophyllum nodosum, a dioecious, long-lived species (Aberg1992), with low rates of recruitment rate and slow growth rate (Aberg \& Pavia 1997, Cervin et al. 2005) has been the focus of a number of long term studies in the NE and NW Atlantic (e.g. Jenkins et al. 1999a,b, 2004, Cervin et al. 2005, Ingolffson \& Hawkins 2008, Araújo et al. 2012). Araújo et al. (2012) showed that the impacts of human trampling can have long term (5 years) effects on understorey community structure in stands of Ascophyllum nodosum. Even small scale $(25 \times 25 \mathrm{~cm})$ disturbance events can have long lasting effects on Ascophyllum understorey communities (Cervin et al. 2005); small scale loss of Ascophylum canopy led to a change in community structure still apparent after 7 years. Such effects can occur despite recovery of the long lived biomass dominants. Schiel \& Lilley (2011) showed differences between disturbed and control understory communities 8 years after removal of the Hormosira canopy even though this dominant fucoid returned to a nearly closed canopy.

Communities composed of long lived individuals are often described as stable, but in reality may only be stable as a consequence of the long lived nature of their components (Connell \& Sousa 1983). Long term observations following perturbations, especially where dominant biota are long lived, are essential to judge the stability of communities and consequent 
properties of ecosystems (Farrell 1988, Hooper et al. 2005). Hooper et al. (2005) points out that theoretical work on stability has outpaced the ability of empirical work to test predictions, essentially because of the time and resource requirements of long term experimental work required to determine the fate of all adults over at least one complete turnover (Connell \& Sousa 1983). The problem of time scale is one which has dogged the sometimes vigorous debate surrounding the existence, or otherwise, of alternate stable states (see Petraitis \& Dudgeon 2004 for review). The question of whether systems can occupy more than one equilibrium point and hence support different stable communities in the same habitat (Lewontin 1969, Connell \& Sousa 1983, Peterson 1984, Petraitis \& Latham 1999, Petraitis et al. 2009) has been addressed in a number of different marine coastal assemblages including coral reefs (Scheffer et al. 2001), rocky shores (Paine et al. 1985, Petraitis \& Latham 1999), sub-tidal rocky reefs (Simenstad et al. 1978) and soft sediments (van de Koppel et al. 2001). Part of the problem in answering what at first sight seems a relatively simple question is that spatial and temporal scale are an intractable part of defining stability. Connell \& Sousa (1983) argued that experimental tests of stability require long term experiments where 'the fate of all adults of the population or community must either be followed for a minimal period of at least one complete turnover, or their replacement probabilities estimated' (p.808). Others disagree (Peterson 1984, Sutherland 1990) and over the last decade or so Petraitis and co-workers (e.g. Petraitis \& Latham 1999, Petraitis \& Dudgeon 2005, Petraitis et al. 2009) have implemented manipulations which although long term by the standards of this review do not reach the temporal standards defined by Connell \& Sousa (1983). The possibility that mussel beds and stands of Ascophyllum nodosum represent alternative states in sheltered bays of the Gulf of Maine was tested through initiating pulse disturbances (clearance of the Ascophyllum canopy) of different sizes and monitoring successional pathways over a nine year period (Petraitis et al. 2009). The shift from Ascophyllum assemblage to mussel bed in $37 \%$ of large clearances, nine years after disturbance, is argued by Petraitis et al. (2009) to show that these communities represent multiple stable states on the intertidal shore of the Gulf of Maine. They go on to present a conceptual framework which combines this view with the prevailing paradigm of environmentally driven consumer control (Lubchenco \& Menge 1978, Bertness et al. 2002). Irrespective of tests of ecological theory, investigation of how the scale of disturbance affects successional trajectory clearly requires a long term approach in this environment at least, as evidenced by the diversity of successional responses among clearing sizes and sites over a six year period (Petraitis \& Dudgeon 2005). 
The majority of ecological experimentation involves small scale, controlled manipulation, which, if of sufficient duration, may give insight into the time scale of recovery of marine communities following perturbation. However, Schiel and Lilley (2011) point out the limitation of such approaches in understanding recovery at coast-wide scales, where propagule supply may be limiting. Underwood (1998, p.292) makes a cogent argument to 'grab opportunities afforded by dramatic events, such as unusually severe weather and largescale changes brought about by natural agents' to enable a longer term and larger scale approach to ecology. Observations, over temporal and spatial scales well beyond standard controlled experiments following mass die-offs (Levitan 1988, Linares et al. 2005), large disturbance events such as ice scour (McCook \& Chapman 1997), storms (Hughes 1989, Underwood 1998), earthquakes (Castilla 1988), human management intervention (Hughes et al. 2009) and pollution (Southward \& Southward 1978) have created insight into ecological processes. McCook and Chapman (1997) assessed the impacts of large scale ice scouring on exposed rocky shores in Nova Scotia over a 5 year period, and showed that many experimental effects noted over shorter time scales (McCook \& Chapman 1991,1992) were not apparent after longer periods, suggesting that much of the variation within the exposed shore habitat is temporary. They also argue that the temporal dominance of Fucus observed over mussels over a 5 year period, and no evidence of competitive superiority by mussels, should lead to caution in assuming any general applicability of previously stated general models of community structure based on the work of Menge and Sutherland $(1976,1987)$. Such conclusions, based on long term observations following large scale perturbations, present a cautionary note to basing environmental management advice on a theoretical framework based predominantly on the short term and small scale. Underwood (1998) makes the point that observations following disturbance can give rise to hypotheses regarding mechanisms which can then be tested through small scale, shorter term experiments. He observed variable rates of recovery in the canopy alga Hormosira banksii over a seven year period following an extremely large storm and then used short term experimental manipulations to test two alternative models: 1 ) that the rate of recovery was a function of the severity of disturbance; 2) recovery was determined by the activities of grazers. A similar combined approach was taken by Carroll and Highsmith (1996). A severe freeze in Alaska coincided with a spring low tide series leading to high levels of mussel mortality, but little 
effect on the mussels' principal predator Nucella lima which winters in the sub-tidal. A combination of observations over 3 years and experimental manipulations demonstrated that the extreme event 'set the framework for a shift in balance of the interaction' between predator and prey (Carroll \& Highsmith 1996, p.130). In the presence of high numbers of $N$. lima, mussels were unable to recover over a 3 year period despite annual recruitment events.

One type of 'experiment' in coastal marine environments which by its nature tends to be long term is the implementation of Marine Protected Areas (MPA's). By totally or partially excluding the extractive activities of humans (Sciberras et al. 2015) MPA's establish a (usually) large scale experiment (Castilla 1999, Diaz et al. 2003) which can be used for understanding long-term dynamics (Castilla 2000) and has led to enormous ecological insight in coastal marine systems, particularly into the prevalence, time scale and magnitude of trophic cascades (reviewed by Castilla 1999). For example in Chile, Duran and Castilla (1989) report the results of a five year study of the consequences of exclusion of human food gatherers from the rocky intertidal and shallow sub-tidal at Las Cruces in central Chile. The cessation of human exploitation of the carnivorous muricid gastropod Concholepas concholepas or 'loco' led to significant enhancement of its density and consequent strong predatory control of previously dominating mussels. These cascading effects resulted in an elevation of intertidal diversity and subsequent domination by barnacles.

The majority of marine reserves or protected areas are established to protect fisheries-targeted species, including benthic organisms such as lobsters, scallops, abalone and the Chilean 'loco'. Such organisms are generally long lived relative to the majority of benthic organisms studied in perturbation experiments. Because the focus of MPA studies has often been to establish effects on these relatively long lived target species (e.g. Duran \& Castilla 1989, Hoskin et al. 2011), and because the temporal scale of the press manipulation (reduction or elimination of human disturbance) is not limited by the normal drivers of ecological experimentation (e.g. researchers funds), it is not surprising that published studies of MPAs are often long term. Harvested species may show a significant lag in response (e.g. BeukersStewart et al. 2005), but benthic prey may also show many years to respond to enhanced predation. For example sea urchins can take many years to respond to changes in predator numbers, (e.g. 13 years in New Zealand, 7 years, in Tasmania, 15 years in Kenya; see Babcock et al. 2010 and references therein). Thus indirect effects on organisms that occur through cascading trophic interactions can take substantially longer to develop than direct effects (Babcock et al. 2010). This observation may explain why species assemblages in 
older reserves often differ from recently created reserves (Micheli et al. 2004) and could lead to failure to identify trophic cascades owing to a lack of sufficient temporal scale (Shears \& Babcock 2003).

The large scale, uncontrolled nature of MPA experiments can lead to considerable insight into the nature of the relationship between environmental and biotic drivers of community state when observations are conducted over sufficient time scale (Babcock et al. 2010, Fraschetti et al. 2013). Fraschetti et al. (2013, p.11) consider a long term approach is essential because 'ecological components may respond differently and over varying temporal scales'. They used a nine year series of observations inside and outside an MPA in SE Italy to examine the role of protection in determining temporal and spatial variability. They showed that protected assemblages, with relatively long lived invertebrates and macroalgae, displayed spatial and temporal homogeneity in marked contrast to a mosaic of changing disturbed patches outside the MPA. Thus, at a local scale, protection enhanced community stability. However, there were also a number of idiosyncratic results, where the effects of protection did not match expectations. Here, it is likely that multiple processes, some derived from variation in environmental context, were acting simultaneously. Similarly Shears and Babcock (2003) demonstrated long term effects ( 25 years) of protection in a trophic cascade in the Leigh marine reserve in New Zealand mediated through the decline of urchins. However, urchin decline was also observed over the short term (possibly as a consequence of disease) at some unprotected sites.

Studies of the effect of protection from human disturbance are often made at a single point in time through comparison of protected and unprotected sites, often many years after establishment of the protection regime. Although suffering from difficulties in firmly ascribing observed spatial differences to protection effects (Underwood 1991), these studies are logistically relatively easy to implement and can (limitations accepted) give important long term insight. For example Mumby et al. (2006) sampled fish and benthic assemblages of Caribbean reef systems 18 years after implementation of a fishing ban. A net doubling of grazing pressure from parrot fishes in protected areas led to a four-fold reduction in macroalgal cover (Mumby et al. 2006) and consequently a two fold increase in coral recruitment (Mumby et al. 2007). Clearly such observations tell us nothing of the rate of change in fish or benthic assemblages, nor the temporal dynamic between interacting species, but does demonstrate the strong top down control exerted by key fish consumers in supporting the health of Caribbean coral reefs. As a note of caution to accepting conclusions based on 
such an approach, a review of six time series studies showed that increases in target species following protection were not always as high as expected on the basis of studies with no temporal replication (Babcock et al. 2010). Thus, understanding how communities change through time following protection is likely to lead to a far greater mechanistic understanding of protection effects.

\section{Conclusions}

It is clear from our review of experimental duration over 33 years, that the majority of manipulative experiments in benthic systems, examining community or population responses of macro-organisms, are reasonably short (two years or less). It is also clear, from reviewing a range of experiments operating over a longer time scale, that a long term approach can yield considerable insight, and in many cases alter conclusions based on the same experiments conducted over shorter time scales. Thus we argue that although many short studies will be perfectly valid, in general, increasing the period over which observations are made following experimental manipulations will yield important benefits.

Limitations on the temporal extent of marine benthic experiments are numerous, and range from the logistical to considerations of motive and reward. Raffaelli and Moller (2000) showed through interviews of experimentalists that decisions regarding duration of field experiments were predominantly pragmatic. Temporal scale was often based on the time available in a studentship, or grant, or the difficulties of maintaining the experiment in a hostile environment. However, there are a number of simple, practical approaches that can be implemented to lengthen experimental duration. First and foremost when planning manipulative field experiments Diaz et al. (2003) stress the need for foresight and the acquisition of long-term funding where possible. However, extending sampling regimes may not necessarily be costly. A common approach where the temporal scale has been extended is to sample at regular intervals over the first year or so of an experiment and then sample at much lower frequencies over a number of years (e.g. Jenkins et al. 2004, Viejo 2009). Extending an experiment over multiple years generally requires some foresight in experimental establishment (e.g. use of secure, non corrosive, preferably stainless steel, markers and a mapping system of spatial replicates which can be utilised by persons other than the original experimenter), plus the motivation to revisit experimental sites over multiple 
years. This can be achieved long after the original experimenter (e.g. student, post-doctoral scientist) has moved on to new pastures.

In promoting a longer term approach to experimentation it is reasonable to consider the role of reviewers and editors. Working over an appropriate temporal scale to address the question posed is an integral part of experimental design and hence should be considered as an issue ranking in importance alongside appropriate replication and independence of sampling units. Whether it currently is, or not, is debatable. That may be because the question is much less tangible. It is always likely that extending an experiment will give additional insight but the cost-benefit relationship of extended monitoring for potentially marginal gains is probably complex and difficult to pin down. However, it is clear from the review of long term studies above, that an increased mechanistic understanding of marine ecological processes can be gained from a longer term approach and understanding the longer-term consequences of impacts on benthic systems is a crucial part of determining management options in the face of global change.

\section{Acknowledgements}

This work was supported by a Brazilian FAPESP Visiting Researcher grant to the first author. Facilities were kindly supplied by the Departamento de Ciências do Mar, Universidade Federal de São Paulo - Campus Baixada Santista, Brazil. The manuscript was much improved by the comments of five anonymous reviewers.

\section{References}

Aberg P (1992) Size based demography of the seaweed Ascophyllum nodosum in stochastic environments. Ecology 73:1488-1501

Aberg P, Pavia H (1997) Temporal and multiple scale variation in juvenile and adult abundance of the brown alga Ascophyllum nodosum. Mar Ecol Prog Ser 158:111-119

Araújo RM, Sousa-Pinto I, Serrão EA, Åberg P (2012) Recovery after trampling disturbance in a canopy-forming seaweed population. Mar Biol 159:697-707 
Babcock RC, Shears NT, Alcala AC, Barrett NS, Edgar GJ, Lafferty KD, McClanahan TR, Russ GR (2010) Decadal trends in marine reserves reveal differential rates of change in direct and indirect effects. Proc Natl Acad Sci USA 107:18256-18261

Barnes DKA (1996) Low levels of colonisation in Antarctica: the role of bryozoans in early community development. In: Gordon D, Smith A, Grant-Mackie A (eds) Bryozoans in space and time. National Institute of Water \& Atmospheric Research Ltd. Wellington, p 19-28

Benedetti-Cecchi L (2003) The importance of the variance around the mean effect size of ecological processes. Ecology 84:2335-2346

Bertness MD, Callaway R (1994) Positive interactions in communities. Trends Ecol Evol 9:191-193

Bertness MD, Trussell GC, Ewanchuk PJ, Silliman BR (2002) Do alternate stable community states exist in the Gulf of Maine rocky intertidal zone? Ecology 83:3434-3448

Beuchel F, Gulliksen B (2008) Temporal patterns of benthic community development in an Arctic fjord (Kongsfjorden, Svalbard): results of a 24-year manipulation study. Polar Biology 31:913-924

Beukers-Stewart BD, Vause BJ, Mosley MWJ, Rossetti HL, Brand AR (2005) Benefits of closed area protection for a population of scallops. Mar Ecol Prog Ser 298:189-204,

Broitman BR, Navarrete SA, Smith F, Gaines SD (2001) Geographic variation of southeastern Pacific intertidal communities. Mar Ecol Prog Ser 224:21-34

Carroll ML, Highsmith RC (1996) Role of catastrophic disturbance in mediating NucellaMytilus interactions in the Alaskan rocky intertidal. Mar Ecol Prog Ser 138:125-133

Castilla JC (1988) Earthquake-caused coastal uplift and its effects on rocky intertidal kelp communities. Science 242:440-443

Castilla JC (1999) Coastal marine communities: trends and perspectives from humanexclusion experiments. Trends Ecol Evol 14:280-283

Castilla JC (2000) Roles of experimental marine ecology in coastal management and conservation. J Exp Mar Biol Ecol 250:3-21

Castilla JC, Bustamante R (1989) Human exclusion from rocky intertidal of Las-Cruces, central Chile - effects on Durvillaea-antarctica (Phaeophyta, durvilleales). Mar Ecol Prog Ser 50:203-214

Cervin G, Aberg P, Jenkins SR (2005) Small-scale disturbance in a stable canopy dominated community: implications for macroalgal recruitment and growth. Mar Ecol Prog Ser 305:31-40

Chapman MG (2013) Constructing replacement habitat for specialist and generalist molluscsthe effect of patch size. Mar Ecol Prog Ser 473:201-214

Coleman RA, Underwood AJ, Benedetti-Cecchi L, Aberg P, Arenas F, Arrontes J, Castro J, Hartnoll RG, Jenkins SR, Paula J, Della Santina P, Hawkins SJ (2006) A continental scale evaluation of the role of limpet grazing on rocky shores. Oecologia 147:556-564

Connell JH (1961) The influence of interspecific competition and other factors on the distribution of the barnacle Chthamalus stellatus. Ecology 42:710-723

Connell JH (1972). Community interactions on marine rocky intertidal shores. Annu Rev Ecol Syst 3: 169-192

Connell JH, Slayter RO (1977) Mechanisms of succession in natural communities and their role in community stability and organization. Am Nat 111:1119-1144 
Connell JH, Sousa WP (1983) On the evidence needed to judge ecological stability or persistence Am Nat 121:789-824

Connell SD (2005) Assembly and maintenance of subtidal habitat heterogeneity: synergistic effects of light penetration and sedimentation. Mar Ecol Prog Ser 289:53-61

Connell SD, Foster MS, Airoldi L (2014) What are algal turfs? Toward a better understanding of turfs. Mar Ecol Prog Ser 495:299-307

Connolly SR, Roughgarden J (1998) A latitudinal gradient in northeast Pacific intertidal community structure: Evidence for an oceanographically based synthesis of marine community theory. Am Nat 151:311-326

Crowe TP, Bracken MES, O’Connor NE (2012) Reality check: issues of scale and abstraction in biodiversity research and potential solutions. In: Solan M, Aspden R, Paterson D (eds) Marine biodiversity and ecosystem functioning: frameworks, methodologies and integration. Oxford University Press Oxford

Davis AR, Ward DW (2009) Establishment and persistence of species-rich patches in a species-poor landscape: role of a structure-forming sub-tidal barnacle. Mar Ecol Prog Ser 380:187-198

Dayton PK (1975) Experimental evaluation of ecological dominance in a rocky intertidal algal community. Ecol Monogr 45:137-159

Dayton PK (1989) Inter-decadal variation in an Antarctic sponge and its predators from oceanographic climate shifts. Science 245:1484-1486

Dayton PK, Oliver JS (1977) Antarctic soft-bottom benthos in oligotrophic and eutrophic environments. Science 197:55-58

Diaz S, Symstad AJ, Chapin FS, Wardle DA, Huenneke LF (2003) Functional diversity revealed by removal experiments. Trends Ecol Evol 18:140-146

Duffy JE, Stachowicz JJ, Bruno JF (2012) Multi-trophic biodiversity and the responses of marine ecosystems to global change In: Solan M, Aspden R, Paterson D (eds) Marine biodiversity and ecosystem functioning: frameworks, methodologies and integration. Oxford University Press, Oxford

Duran LR, Castilla JC (1989) Variation and persistence of the middle rocky intertidal community of central Chile, with and without human harvesting. Mar Biol 103:555562

Dye AH (1998) Community-level analyses of long-term changes in rocky littoral fauna from South Africa. Mar Ecol Prog Ser 164:47-57

Ellis J, Schneider DC (2008) Spatial and temporal scaling in benthic ecology. J Exp Mar Biol Ecol 366:92-98

Farrell TM (1988) Community stability: effects of limpet removal and reintroduction in a rocky intertidal community. Oecologia 75:190-197

Feldman KL, Armstrong DA, Eggleston DB, Dumbauld BR (1997) Effects of substrate selection and post-settlement survival on recruitment success of the thalassinidean shrimp Neotrypaea californiensis to inter-tidal shell and mud habitats. Mar Ecol Prog Ser 150:121-136

Fraschetti S, Guarnieri G, Bevilacqua S, Terlizzi A, Boero F (2013) Protection enhances community and habitat stability: evidence from a Mediterranean marine protected area. Plos ONE 8(12): e81838. doi:10.1371/journal.pone.0081838

Goodsell PJ, Connell SD (2005) Historical configuration of habitat influences the effects of disturbance on mobile invertebrates. Mar Ecol Prog Ser 299:79-87 
Grant DL, Clarke PJ, Allaway WG (1993) The response of grey mangrove (Avicennia marina (Forsk.) Vierh.) seedlings to spills of crude oil. J Exp Mar Biol Ecol 171: 273-295.

Green DS, Crowe TP (2013) Physical and biological effects of introduced oysters on biodiversity in an intertidal boulder field. Mar Ecol Prog Ser 482:119-132

Holmes NJ, Harriott VJ, Banks SA (1997) Latitudinal variation in patterns of colonisation of cryptic calcareous marine organisms. Mar Ecol Prog Ser 155:103-113

Hooper DU, Chapin FS, Ewel JJ, Hector A, Inchausti P, Lavorel S, Lawton JH, Lodge DM, Loreau M, Naeem S, Schmid B, Setala H, Symstad AJ, Vandermeer J, Wardle DA (2005) Effects of biodiversity on ecosystem functioning: A consensus of current knowledge. Ecol Monogr 75:3-35

Hoskin MG, Coleman RA, von Carlshausen E, Davis CM (2011) Variable population responses by large decapod crustaceans to the establishment of a temperate marine notake zone. Can J Fish Aquat Sci 68:185-200

Hughes TP Community structure and diversity of coral reefs: the role of history. Ecology 70 : 275-279

Hughes RG, Fletcher PW, Hardy MJ (2009) Successional development of saltmarsh in two managed realignment areas in SE England, and prospects for saltmarsh restoration. Mar Ecol Prog Ser 384:13-22

Incera M, Bertocci I, Benedetti-Cecchi L (2010) Effects of mean intensity and temporal variability of disturbance on the invasion of Caulerpa racemosa var. cylindracea (Caulerpales) in rock pools. Biol Inv 12:501-514

Incera M, Olabarria C, Troncoso JS, Lopez J (2009) Response of the invader Sargassum muticum to variability in nutrient supply. Mar Ecol Prog Ser 377:91-101

Ingolfsson A, Hawkins SJ (2008) Slow recovery from disturbance: a 20 year study of Ascophyllum canopy clearances. J Mar Biol Assoc UK 88:689-691

Jacobs R (1980) Effects of the Amoco-Cadiz oil-spill on the seagrass community at Roscoff with special reference to the benthic infauna. Mar Ecol Prog Ser 2:207-212

Jenkins SR (2009) Settlement and recruitment In: M W (ed) Marine Hard Bottom Communities: Patterns, Dynamics, Diversity and Change. Springer, Verlag

Jenkins SR, Arenas F, Arrontes J, Bussell J, Castro J, Coleman RA, Hawkins SJ, Kay S, Martinez B, Oliveros J, Roberts MF, Sousa S, Thompson RC, Hartnoll RG (2001) European-scale analysis of seasonal variability in limpet grazing activity and microalgal abundance. Mar Ecol Prog Ser 211:193-203

Jenkins SR, Coleman RA, Della Santina P, Hawkins SJ, Burrows MT, Hartnoll RG (2005) Regional scale differences in the determinism of grazing effects in the rocky intertidal. Mar Ecol Prog Ser 287:77-86

Jenkins SR, Hawkins SJ, Norton TA (1999a) Direct and indirect effects of a macroalgal canopy and limpet grazing in structuring a sheltered inter-tidal community. Mar Ecol Prog Ser 188:81-92

Jenkins SR, Norton TA, Hawkins SJ (1999b) Interactions between canopy forming algae in the eulittoral zone of sheltered rocky shores on the Isle of Man. J Mar Biol Assoc UK 79:341-349

Jenkins SR, Norton TA, Hawkins SJ (2004) Long term effects of Ascophyllum nodosum canopy removal on mid shore community structure. J Mar Biol Assoc UK 84:327-329

Jewett EB, Hines AH, Ruiz GM (2005) Epifaunal disturbance by periodic low levels of dissolved oxygen: native vs. invasive species response. Mar Ecol Prog Ser 304:31-44 
Kaehler S, Williams GA (1997) Do factors influencing recruitment ultimately determine the distribution and abundance of encrusting algae on seasonal tropical shores? Mar Ecol Prog Ser 156:87-96

Keough MJ, Downes BJ (1982) Recruitment of marine-invertebrates - the role of active larval choices and early mortality. Oecologia 54:348-352

Kilar JA, McLachlan J (1989) Effects of wave exposure on the community structure of a plant-dominated, fringing-reef platform - intermediate disturbance and disturbancemediated competition. Mar Ecol Prog Ser 54:265-276

Konar B (2007) Recolonization of a high latitude hard-bottom nearshore community. Polar Biology 30:663-667

Leonard GH (1999) Positive and negative effects of intertidal algal canopies on recruitment and survival of barnacles. Mar Ecol Prog Ser 178:241-249

Levin S (1992) The problem of pattern and scale in ecology. Ecology 72:1943-1967

Levitan DR (1988) Algal-urchin biomass responses following mass mortality of Diadema antillarum Philippi at Saint John, U.S. Virgin Islands. J Exp Mar Biol Ecol 119:167-178

Lewontin RC (1969) The meaning of stability. In: Woodwell G, Smith H (eds) Diversity and stability in ecological systems. Brookhaven National Laboratory, Upton, NY., p 12-24

Linares C, Coma R, Diaz D, Zabala M, Hereu B, Dantart L (2005) Immediate and delayed effects of a mass mortality event on gorgonian population dynamics and benthic community structure in the NW Mediterranean Sea. Mar Ecol Prog Ser 305:127-137

Lindegarth M, Aberg P, Cervin G, Nilsson PG (2001) Effects of grazing on the structure of mid-shore, inter-tidal assemblages on moderately exposed rocky shores of the Swedish west coast. Mar Ecol Prog Ser 212:29-38

Lubchenco J, Menge BA (1978) Community development and persistence in a low rocky intertidal zone. Ecol Monogr 48:67-94

Maggi E, Bertocci I, Vaselli S, Benedetti-Cecchi L (2009) Effects of changes in number, identity and abundance of habitat-forming species on assemblages of rocky seashores. Mar Ecol Prog Ser 381:39-49

Maggi E, Bulleri F, Bertocci I, Benedetti-Cecchi L (2012) Competitive ability of macroalgal canopies overwhelms the effects of variable regimes of disturbance. Mar Ecol Prog Ser 465:99-109

McCook, LJ Chapman ARO (1991) Community succession following massive ice scour on an exposed rocky shore : effects of Fucus canopy algae and of mussels during late succession. J Exp Mar Biol Ecol 154:137-169

McCook LJ, Chapman ARO (1992) Vegetative regeneration of Fucus rockweed canopy as a mechanism of secondary succession on an exposed rocky shore. Bot Mar 35:35-

McCook LJ, Chapman ARO (1997) Patterns and variations in natural succession following massive ice-scour of a rocky intertidal seashore. J Exp Mar Biol Ecol 214:121-147

Menge BA (1997) Detection of direct versus indirect effects: Were experiments long enough? Am Nat 149:801-823

Menge BA, Daley BA, Wheeler PA, Dahlhoff E, Sanford E, Strub PT (1997) Benthic-pelagic links and rocky intertidal communities: Bottom-up effects on top-down control? Proc Natl Acad Sci USA 94:14530-14535

Menge BA, Lubchenco J, Bracken MES, Chan F, Foley MM, Freidenburg TL, Gaines SD, Hudson G, Krenz C, Leslie H, Menge DNL, Russell R, Webster MS (2003) Coastal 
oceanography sets the pace of rocky intertidal community dynamics. Proc Natl Acad Sci USA 100:12229-12234

Menge BA, Sanford E, Daley BA, Freidenburg TL, Hudson G, Lubchenco J (2002) Interhemispheric comparison of bottom-up effects on community structure: Insights revealed using the comparative-experimental approach. Ecol Res 17:1-16

Menge BA, Sutherland JP (1976) Species diversity gradients: synthesis of the roles of predation, competition and temporal heterogeneity. Am Nat 110:351-369

Menge BA, Sutherland JP (1987) Community regulation: Variation in disturbance, competition and predation in relation to environmental stress and recruitment. Am Nat 130:730-757

Methratta ET, Petraitis PS (2008) Propagation of scale-dependent effects from recruits to adults in barnacles and seaweeds. Ecology 89:3128-3137

Micheli F, Halpern BS, Botsford LW, Warner RR (2004) Trajectories and correlates of community change in no-take marine reserves. Ecol Appl 14:1709-1723

Miller MW, Valdivia A, Kramer KL, Mason B, Williams DE, Johnston L (2009) Alternate benthic assemblages on reef restoration structures and cascading effects on coral settlement. Mar Ecol Prog Ser 387:147-156

Minchinton TE, Fels KJ (2013) Sediment disturbance associated with trampling by humans alters species assemblages on a rocky intertidal seashore. Mar Ecol Prog Ser 472:129140

Mumby PJ, Dahlgren CP, Harborne AR, Kappel CV, Micheli F, Brumbaugh DR, Holmes KE, Mendes JM, Broad K, Sanchirico JN, Buch K, Box S, Stoffle RW, Gill AB (2006) Fishing, trophic cascades, and the process of grazing on coral reefs. Science 311:98101

Mumby PJ, Harborne AR, Williams J, Kappel CV, Brumbaugh DR, Micheli F, Holmes KE, Dahlgren CP, Paris CB, Blackwell PG (2007) Trophic cascade facilitates coral recruitment in a marine reserve. Proc Natl Acad Sci USA 104:8362-8367

Naeem S (2008) Advancing realism in biodiversity research. Trends in Ecology and Evolution 23:414-416

Nelson WG (1981) Experimental studies of decapod and fish predation on seagrass macrobenthos. Mar Ecol Prog Ser 5:141-149

O'Connor NE, Crowe TP (2005) Biodiversity loss and ecosystem functioning: Distinguishing between number and identity of species. Ecology 86:1783-1796

Oliveira JP, Sousa-Pinto I, Weber GM, Bertocci I (2014) Interplay of experimental harvesting and climate-related disturbance on benthic assemblages of rocky seashores. Mar Ecol Prog Ser 495:131-142

Paine RT (1966) Food web complexity and species diversity. Am Nat 100:65-75

Paine, R. (1977). Controlled manipulations in the marine intertidal zone and their contributions to ecological theory. In: Goulden CE (ed) Changing scenes in natural sciences 1776-1976. Academy of Natural Sciences, Philadelphia, PA, 245-270.

Paine RT (1994) Marine rocky shores and community ecology: an experimentalist's perspective. In: Kinne O. (ed.) Excellence in Ecology 4. Ecology Institute, D-21385 Oldendorf/Luhe, Germany

Paine RT, Castillo JC, Cancino J (1985) Perturbation and recovery patterns of starfishdominated intertidal assemblages in Chile, New Zealand, and Washington State. Am Nat 125:679-691 
Peterson CH (1984) Does a rigorous criterion for environmental identity preclude the existence of multiple stable points? Am Nat 124:127-133

Petraitis PS, Dudgeon SR (2004) Detection of alternative stable states in marine communities. J Exp Mar Biol Ecol 300:343- 371

Petraitis PS, Dudgeon SR (2005) Divergent succession and implications for alternative states on rocky intertidal shores. J Exp Mar Biol Ecol 326:14 - 26

Petraitis PS, Latham RE (1999) The importance of scale in testing the origins of alternative community states. Ecology 80: 429 - 442

Petraitis PS, Methratta ET, Rhile EC, Vidargas NA, Dudgeon SR (2009) Experimental confirmation of multiple community states in a marine ecosystem. Oecologia 161:139148

Raffaelli DG (2006) Biodiversity and ecosystem functioning: issues of scale and trophic complexity. Mar Ecol Prog Ser 311:285-294

Raffaelli DG, Hawkins SJ (1996) Intertidal ecology. Chapman and Hall, London

Raffaelli DG, Moller H (2000) Manipulative experiments in animal ecology-Do they promise more than they can deliver? Adv Ecol Res 30:299-330

Reinhardt JF, Whitlatch RB, Osman RW (2013) Effects of temperature on the recruitment phenology and niche overlap of shallow epifaunal assemblages in southern New England. Mar Ecol Prog Ser 489:61-74

Ruiz JM, Romero J (2001) Effects of in situ experimental shading on the Mediterranean seagrass Posidonia oceanica. Mar Ecol Prog Ser 215:107-120

Russell BD, Connell SD (2005) A novel interaction between nutrients and grazers alters relative dominance of marine habitats. Mar Ecol Prog Ser 289:5-11

Sanford E (1999) Regulation of keystone predation by small changes in ocean temperature. Science 283:2095-2097

Scheffer M, Carpenter S, Foley JA, Folke C, Walker B (2001) Catastrophic shifts in ecosystems. Nature 413:591 - 596

Schiel DR, Lilley SA (2011) Impacts and negative feedbacks in community recovery over eight years following removal of habitat-forming macroalgae. J Exp Mar Biol Ecol 407:108-115

Schneider DC (2001) The rise of the concept of scale in ecology. Bioscience 51:545-553

Sciberras M, Jenkins SR, Kaiser MJ, Hawkins SJ, Pullin AS (2015) Evaluating the relative conservation value of partially and fully protected marine reserves. Fish and Fisheries 16: $58-77$

Shears NT, Babcock RC (2003) Continuing trophic cascade effects after 25 years of no take marine reserve protection. Mar Ecol Prog Ser 246:1-16

Simenstad CA, Estes JA, Kenyon KW (1978) Aleuts, sea otters, and alternate stable state communities. Science 200:403-411

Southward AJ, Southward EC (1978) Recolonization of rocky shores in Cornwall after use of toxic dispersants to clean up the Torrey Canyon spill. J Fish Res Board Can 35:682706

Spivak AC, Canuel EA, Duffy JE, Douglass JG, Richardson JP (2009) Epifaunal community composition and nutrient addition alter sediment organic matter composition in a natural eelgrass Zostera marina bed: a field experiment. Mar Ecol Prog Ser 376:55-67 
Stachowicz JJ, Bracken MES, Graham M (2008b) Complementarity in marine biodiversity manipulations: reconciling divergent evidence from field and mesocosm experiments. Proc Natl Acad Sci 105:18842-18847

Stachowicz JJ, Graham M, Bracken MES, Szoboszlai AI (2008a) Diversity enhances cover and stability of seaweed assemblages: the role of heterogeneity and time. Ecology 89:3008-3019

Sutherland JP (1990) Perturbations, resistance and alternative views of the existence of multiple stable points in nature. Am Nat 136:270-275

Sutherland JP, Karlson RH (1977) Development and stability of fouling community at Beaufort, North-Carolina. Ecol Monogr 47:425-446

Tait LW, Schiel DR (2011) Legacy effects of canopy disturbance on ecosystem functioning in macroalgal assemblages. PloS ONE DOI: 10.1371/journal.pone.0026986

Tegner MJ, Dayton PK, Edwards PB, Riser KL (1997) Large-scale, low-frequency oceanographic effects on kelp forest succession: A tale of two cohorts. Mar Ecol Prog Ser 146:117-134

Underwood AJ (1991) Beyond BACI: Experimental designs for detecting human environmental impacts on temporal variations in natural populations. Aust J Mar Freshwat Res 42:569-587

Underwood AJ (1998) Grazing and disturbance: an experimental analysis of patchiness in recovery from a severe storm by the intertidal alga Hormosira banksii on rocky shores in New South Wales. J Exp Mar Biol Ecol 231:291-306

Underwood AJ (2000) Experimental ecology of rocky intertidal habitats: what are we learning? J Exp Mar Biol Ecol 250:51-76

Valdivia N, Heidemann A, Thiel M, Molis M, Wahl M (2005) Effects of disturbance on the diversity of hard-bottom macrobenthic communities on the coast of Chile. Mar Ecol Prog Ser 299:45-54

Van De Koppel J, Herman PMJ, Thoolen P, Heip CHR (2001) Do alternate stable states occur in natural ecosystems? Evidence from a tidal flat. Ecology 82:3449 - 3461

Viejo RM (2009) Resilience in intertidal rocky shore assemblages across the stress gradient created by emersion times. Mar Ecol Prog Ser 390:55-65

Wiens JA (1989) Spatial scaling in ecology Func Ecol 3:385-397

Yodzis P (1988) The indeterminacy of ecological interactions as perceived through perturbation experiments Ecology 69:508-515 


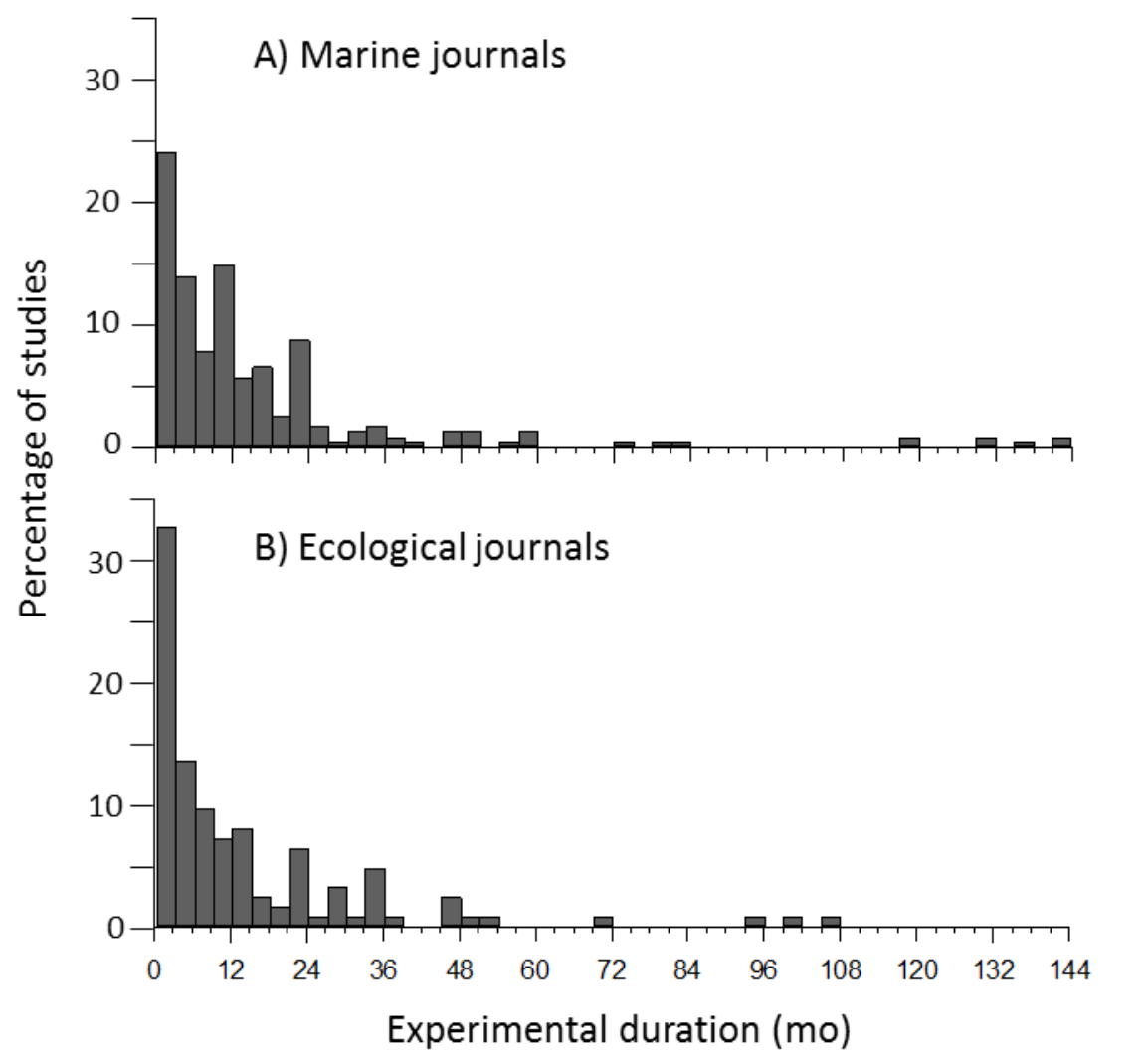

898

899 Figure 1 Frequency histogram indicating the distribution of experimental study duration in 900 (A) marine journals and (B) ecological journals over the period 1980 to 2013.

901

902

903

904 


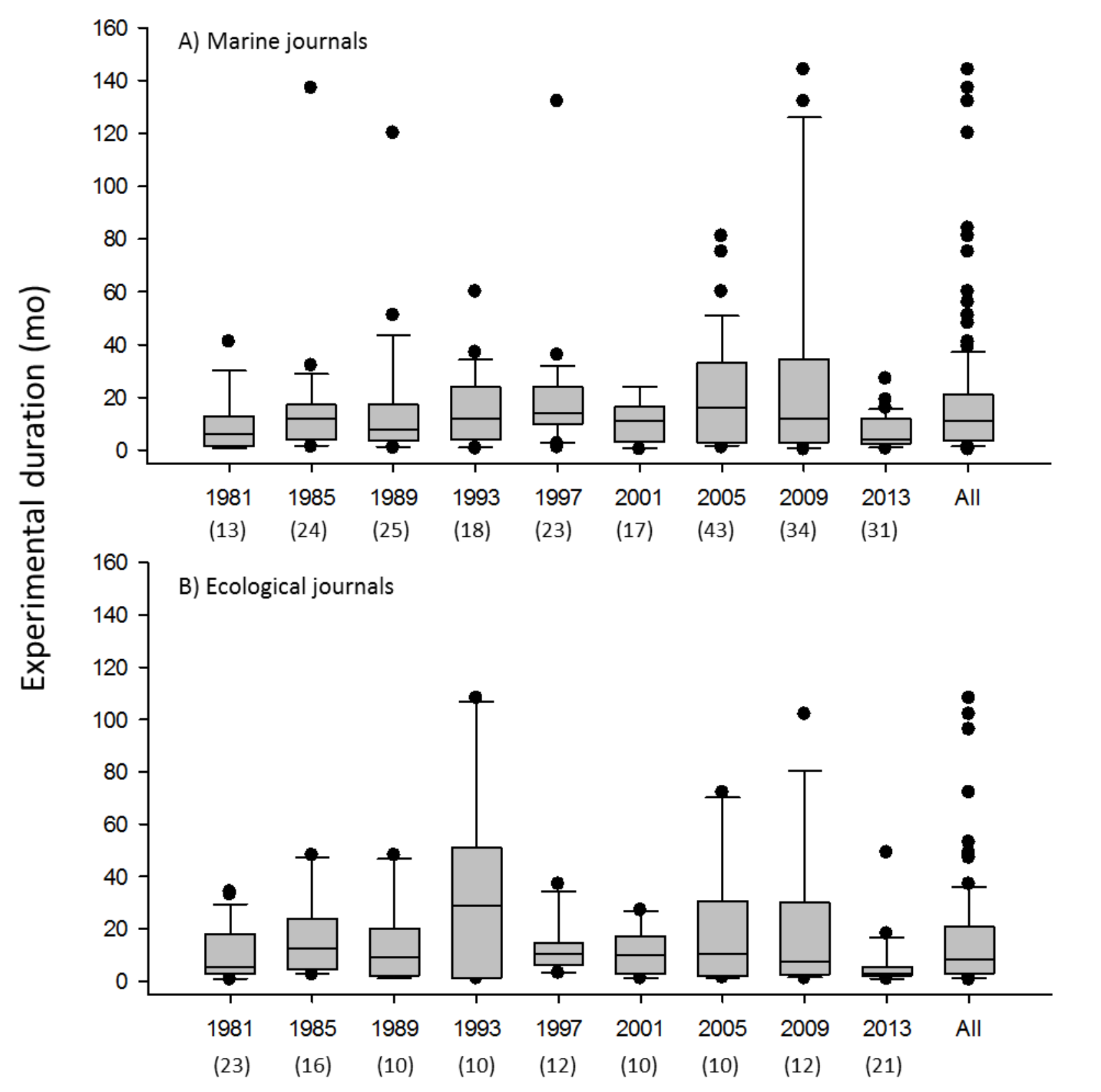

908 Figure 2 Box plot showing the duration of manipulative experiments over the nine periods 909 examined and for all periods combined in (A) marine journals and (B) ecological journals.

910 Boxes indicate the median (horizontal line) and the $25^{\text {th }}$ and $75^{\text {th }}$ percentiles; whiskers indicate 911 the $10^{\text {th }}$ and $90^{\text {th }}$ percentile and black dots the outliers. Number of independent experiments 912 included in the analysis indicated in brackets beneath each year. 

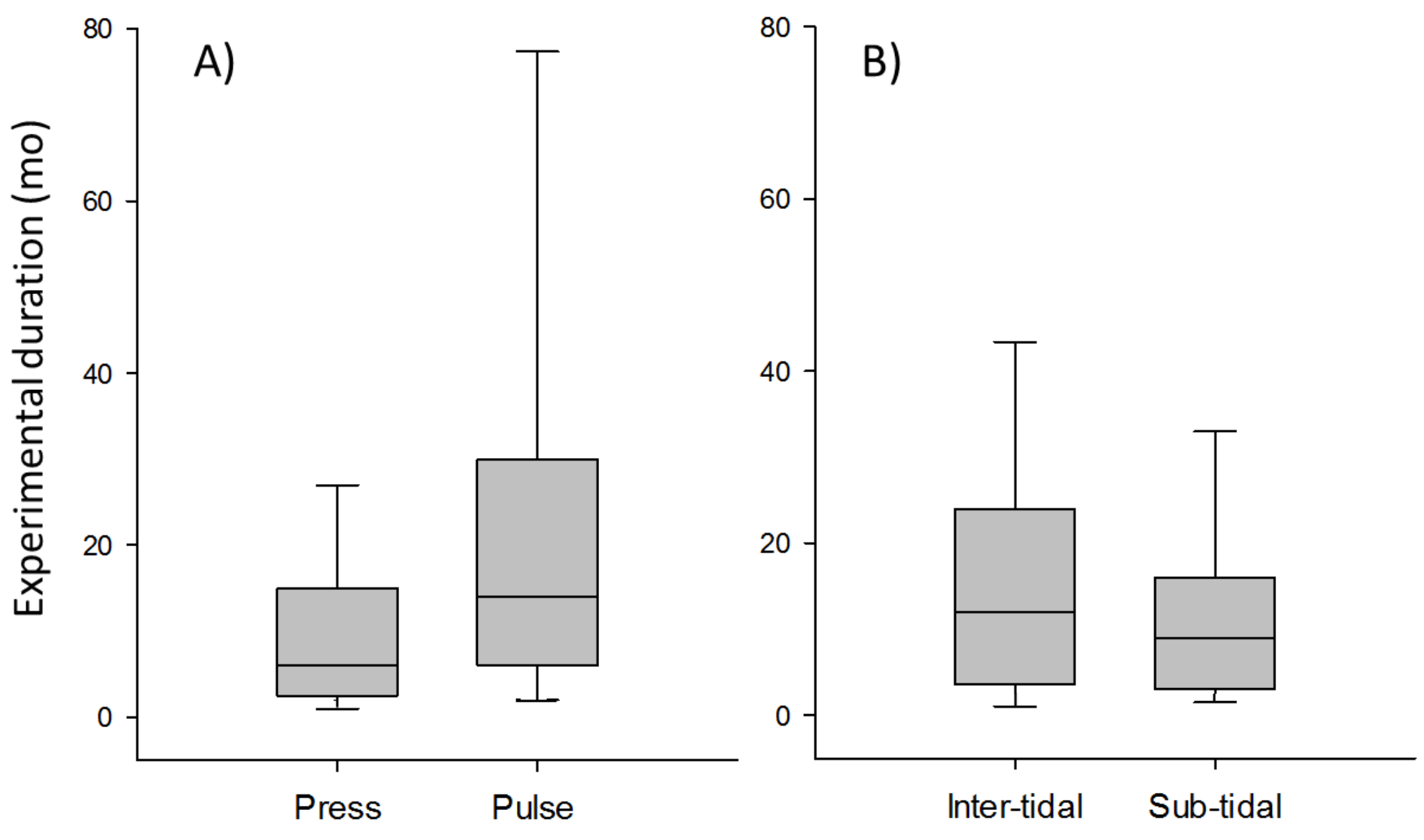

916 Figure 3 Box plots showing median study duration (and $10^{\text {th }}, 25^{\text {th }}, 75^{\text {th }}$ and $90^{\text {th }}$ percentiles)

917 for comparisons among A) press $(n=219)$ and pulse $(n=133)$ studies and B) intertidal $(n=175)$

918 and sub-tidal $(\mathrm{n}=177)$ studies

919

920

921

922 